\title{
Hematopoietic Effect of Phellinus linteus Polysaccharide in Mouse Splenocytes and Bone Marrow Cells
}

\author{
Tae Joon Won, Min Soo Kim, Jong Shick Woo, Sang Beom Han, and Kwang Woo Hwang* \\ Department of Immunology, College of Pharmacy, Chung-Ang University, Seoul 156-756, Korea
}

(Received August 21, 2007/Accepted December 11, 2007)

\begin{abstract}
In anti-cancer therapies, radiotherapy and chemotherapy show a superior inhibition effect on cancer cell growth, but those are very toxic to normal tissues and organs. Particularly, drugs for neutropenia, one of chemotherapy agents, which suppress the function of bone marrow, are needed to be controlled in terms of their dosage and therapy period because of their side effect. Phellinus linteus polysaccharide (PL) has been reported to increase the number of splenocytes and bone marrow cells. PL has been shown to decrease the side effects of cyclophosphamide (CYC) treatment to the cancer patients. PL showed no effects in semisolid clonogenic assay, suggesting that PL doesn't contain substantial compounds to substitute for colony stimulating factors (CSFs). On the other hand, PL increased the expression of SCF, IL-3, GM-CSF, TPO genes. These results indicate that PL may promote the growth and proliferation of splenocytes and bone marrow cells through indirect or CSFs-dependent pathway, which may lead to a hematopoiesis.
\end{abstract}

Keywords $\square$ hematopoiesis, Phellinus lintus polysaccharide, splenocytes, bone marrow, colony stimulating factors

\section{INTRODUCTION}

Cancer has been considered as one of incurable diseases, and a lot of researches have focused on curing cancers. Surgery, radiation therapy and chemotherapy have been considered as the major therapeutic modalities commonly used for the treatment of a variety of cancer patients. However, in many cases, those therapeutic modalities induce several side effects such as suppression of bone marrow functions, decrease of immune functions, abnormalities in digestive functions, and weakness (Ito et al., 1979). Particularly, side effects of cancer therapies at bone marrow functions such as decrease of granulocytes could induce the death of the cancer patients due to the infection and septicaemia (Chauvergne et al., 1996; Pronk et al., 1995; Cascinu et al., 1995). Therefore, therapeutic periods and the doses of the chemotherapy should be altered in order to maintain the appropriate number of neutrophils, which indicate the decrease of granulocytes. Recently, immunotherapy, inducer of differentiation and cytokines, has been attracted in cancer therapies. Especially, colony stimulating factors which regulate the growth of bone marrow cells have been employed in clinics

*Corresponding author

Tel: $+82-2-820-5597, \quad$ Fax: $+82-2-823-5597$

E-mail: khwang@cau.ac.kr
(Clark et al., 1987; Bociek et al., 1996; Bokemeyer et al., 1996). However, the application of the recombinant colony stimulating factors to the cancer patients has been restricted due to the side effects on the stimulation of cancer cell growth or toxicity against human being (Naglieri et al., 1998; Ridolfi et al., 1998).

Hematopoiesis is the process which hematopoietic stem cells grow and divide into blood cells. In human, this process carried out in liver and spleen for fetus and in bone marrow for adults. In case of mice and other animals, it occurs in spleen (Dexter et al., 1997). The generation of blood cells is known to be regulated by the direct contact of cells to one another, various hematopoietic stimulating factors and cytokines, but this process is not fully elucidated yet. The hematopoietic stimulating factors not only are essential for the growth and differentiation of blood cells, but also affect on their survival. It has been also reported that the hematopoietic cells undergo the apoptosis without hematopoietic stimulating factors (Jan et al., 1991). The examples of hematopoietic factors are granulocyte/macrophage colony stimulating factor (GM-CSF), granulocyte colony stimulating factor (G-CSF), macrophage colony stimulating factor (M-CSF), stem cell factor (SCF), thrombopoietin (TPO), erythropoietin (EPO), interleukin-1 (IL-1), interleukin-3 (IL-3), and those factors are known to promote the growth and the differentiation of blood cells to specific types of blood cells by affecting bone marrow cells (Brugger et al., 1994; Arai et al., 
1990).

It had been well established that many polysaccharides extracted from plants, fungi, yeast and bacteria show the anticancer activities (Takeda et al., 1969; Kao et al., 1981). Especially, polysaccharides from Basidiomycota have been most widely studied (Chihara et al., 1969). Those from Basidiomycota exert their anti-cancer effects as immunomodulators (Sugiura et al., 1977; Browder et al., 1983; Mansell et al., 1975) and can be used as adjuvant therapy for cancer because those polysaccharides alleviate and prevent the side effects of chemotherapy (Hirose et al., 1993). Particularly, it has been reported that Phellinus linteus (PL) show anti-cancer effect against sarcoma 180 cancer cell line (Ikegawa et al., 1968), decrease the growth rate of solid tumors, and increase the survival of multicancer animal models (Chung et al., 1994). It also exerted the anti-cancer effect by increasing non-specific immune function by working at NK cells. Phellinus linteus showed strong cytotoxic effect in vivo, but weak cytotoxic effect in vitro, suggesting that Phellinus linteus exerts its anti-cancer effect by activating biological functions such as immunity and hematopoiesis (Rhee et al., 2000). Therefore, in the present study, polysaccharides extracted from Phellinus linteus were tested for their effects on the generation of hematopoiesis stimulating factors and the growth of bone marrow and spleen in order to study their hematopoietic effects.

\section{MATERIALS AND METHODS}

\section{Laboratory animals and materials}

Male ICR mouse were purchased from HanLim laboratory and allowed to acclimatize in our facility for one week. The animals were breeding under the conditions of $24 \pm 2^{\circ} \mathrm{C}$, controlled light, and feeding without antibiotics. Phelinus linteus polysaccharide fraction was offered as $500 \mu \mathrm{g} / \mathrm{mL}$. cyclophosphamide (CYC) was purchased from Sigma and diluted to 1.6 $\mu \mathrm{g} / \mathrm{mL}$. All reagents were diluted with 10\% FBS RPMI 1640 for splenocytes and 20\% FBS alpha MEM for bone marrow cells.

\section{MTT assay}

Spleen and thighbone were obtained from mouse sacrificing by enucleating. Each splenocytes and bone marrow cells were separated from these removed tissues. Cells were plated into 96 well culture plates at $1 \times 10^{6}$ cells per well and were treated 500 $\mu \mathrm{g} / \mathrm{mL}$ PL, $1.6 \mu \mathrm{g} / \mathrm{mL}$ CYC, or $500 \mu \mathrm{g} / \mathrm{mL}$ PL plus $1.6 \mu \mathrm{g} / \mathrm{mL}$ CYC. The plates were incubated for $48 \mathrm{hr}$ at $37^{\circ} \mathrm{C}$ in a humidified atmosphere of $5 \% \mathrm{CO}_{2}$. Thereafter, each well was treated with $10 \mu \mathrm{l}$ of methylthiazololetetrazolium (5 $\mathrm{mg} / \mathrm{ml} \mathrm{MTT})$. In order to dissolve the formazan crystals (which is result of previous step), each plate was added $10 \%$ SDS containing $0.01 \mathrm{~N} \mathrm{HCl}$. The optical density was read on a micro plate reader at $570 \mathrm{~nm}$.

\section{Semisolid clonogenic assay}

Splenocytes or bone marrow cells resuspended in semisolid medium as $2 \times 10^{6}$ cells $/ \mathrm{ml}$ concentration were cultured in 35 $\mathrm{mm}$ petri dishes. Semisolid medium was containing Iscove's modified Dulbecco's medium (IMDM) and 1\% agar, 20\% fetal bovine serum and $1.6 \mu \mathrm{g} / \mathrm{mL}$ CYC, $500 \mu \mathrm{g} / \mathrm{mL}$ PL, or $1.6 \mu \mathrm{g} /$ $\mathrm{mL}$ CYC plus $500 \mu \mathrm{g} / \mathrm{mL}$ PL according to sample group. Cell cultures were incubated for 9 days at $37^{\circ} \mathrm{C}$ in a humidified atmosphere with $5 \% \mathrm{CO}_{2}$. Colonies were counted with a microscope.

\section{RT-PCR (reverse transcription - polymerase chain reaction)}

Total RNA was extracted from $10^{7}$ cells using Trizol reagent (Life Technologies, Inc.-BRL, Gaithersburg, MD) according to the protocol provided by the manufacturer and quantified by spectrophotometer $(260 \mathrm{~nm})$. cDNA were synthesized from 1 $\mu \mathrm{g}$ of DNA-free RNA, added to the reverse transcriptase (RT) mixture. In the thermal cycler, tubes were heated at $42^{\circ} \mathrm{C}$ for 60 minutes, $94^{\circ} \mathrm{C}$ for 5 minutes, quickly chilled on ice to $4^{\circ} \mathrm{C}$. The RT reaction product was amplified by PCR using specific primers. Primer sets included the SCF primers 5'-TAACCCTCAACTATGTCGCC-3'(forward) and 5'-CGTGTACAGCTTC AGTTTCC-3'(reverse), and IL-3 primers 5'-GAAGTGGATCCTGAGGACAGATACG-3'(forward) and 5'-GACCCATGG GCCATGAGGAACATTC-3'(reverse), and TPO primers 5'CCTCTTCTTGAGCTTGCAAC-3'(forward) and 5'-AGCCC ATGAGTTCCATTCAC-3'(reverse). PCR was begun with a denaturing step of $94^{\circ} \mathrm{C}$ for 5 minutes, then 34 cycles of 94 for 30 seconds, $55^{\circ} \mathrm{C}$ for 90 seconds and $68^{\circ} \mathrm{C}$ for 60 seconds, and finished with $68^{\circ} \mathrm{C}$ for 10 minutes. For analysis, reaction product was run in $1.8 \%$ agarose gel.

\section{Statistical analysis}

All results are given as mean \pm S.D. Comparison between means was made by Student's $t$ test

\section{RESULTS}

\section{Effect of PL on proliferation of splenocytes and bone mar- row cells}

To confirm whether treatment of PL increased the proliferation of hematopoietic cells, the number of splenocytes and bone 
marrow cells that was treated with PL and/or CYC for $48 \mathrm{hr}$ was assessed by MTT assay (Fig. 1). In splenocytes, the number of cells was increased in the treatment with PL when compared with non-treatment. Although the presence of CYC showed the decrease of cell number because of its cytotoxicity, the addition of PL to the cells treated with CYC statistically increase the proliferation of splenocytes. Similar to the result in splenocytes, we show that addition of PL potently increases the proliferation of bone marrow cells regardless of the presence of CYC. These data demonstrate that the treatment of PL can augment the proliferation of hematopoietic cells.

\section{No effect of PL on colony formation of splenocytes and bone marrow cells}

The ability of PL to increase the cell number in spleen and bone marrow caused us to determine whether PL is capable of directly stimulating the proliferation. Splenocytes and bone
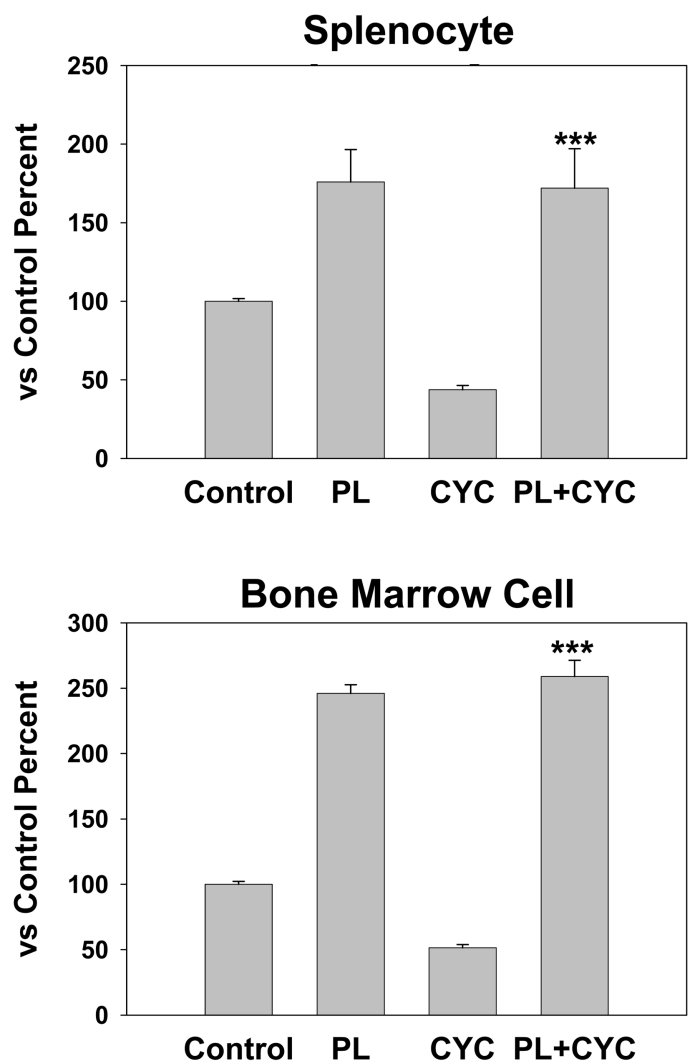

Fig. 1. PL increased the proliferation of spleen and bone marrow cells with or without CYC. Spleen and bone marrow cells were treated $500 \mu \mathrm{g} / \mathrm{ml} \mathrm{PL}$ with or without $1.6 \mu \mathrm{g} / \mathrm{ml}$ CYC for $48 \mathrm{hr}$. Proliferation was analyzed for MTT assay. Results represent the mean and SD of triplicate wells. ***: Significantly different from CYC alone, $p<0.001$. marrow cells were purified and incubated in semisolid culture media with PL, CYC, and PL plus CYC. After 9 days, the colonies were formed by the proliferation of cells and were counted. As shown in Fig. 2, PL slightly increases the colony formation of splenocytes in both the presence and absence of CYC. In bone marrow cells, treatment with PL failed to augment the number of colony when compared with control group. Our observation supports that PL does not directly stimulate the proliferation of hematopoietic cells.

\section{Effect of PL on the expression of hematopoietic factor genes}

After demonstrating that PL is unable to stimulate the increase of cell number directly, we next investigated the effects of PL on the gene expression of hematopoietic stimulating factors such as SCF, IL-3, GM-CSF, and TPO (Fig. 3). In
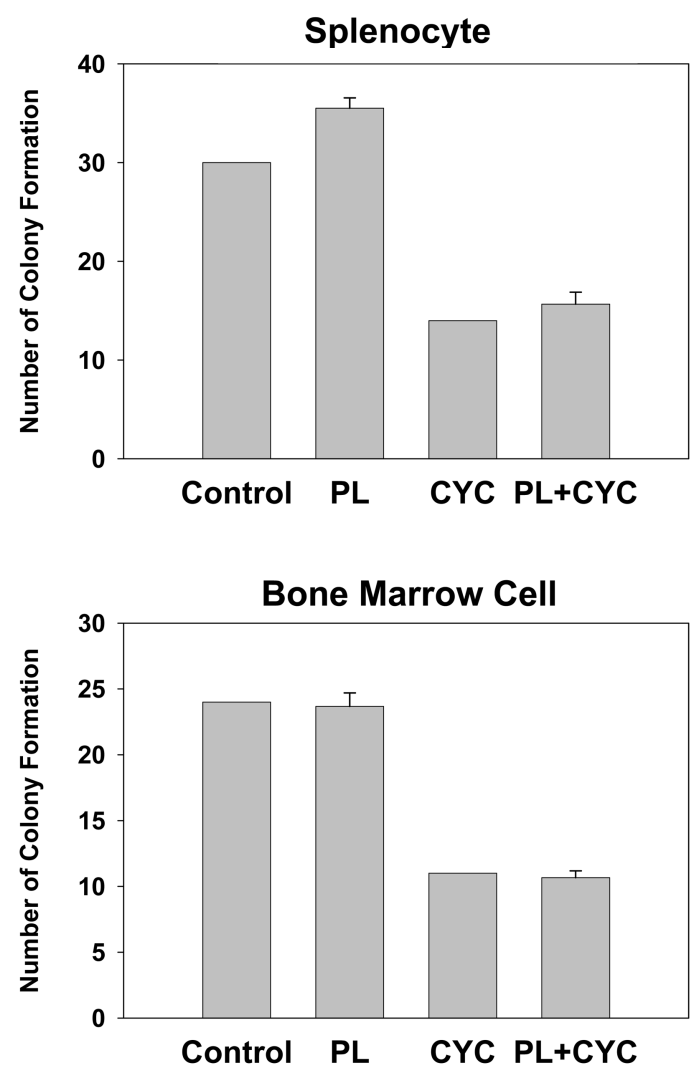

Fig. 2. PL has no effect for colony formation of spleen and bone marrow cells. Spleen and bone marrow cells were incubated in semisolid culture medium that was treated $500 \mu \mathrm{g} /$ $\mathrm{ml} \mathrm{PL}$ with or without $1.6 \mu \mathrm{g} / \mathrm{ml} \mathrm{CYC}$. After 9 days, the number of colonies grown in semisolid agar plate was scored. Results represent the mean and SD of three independent experiments. 


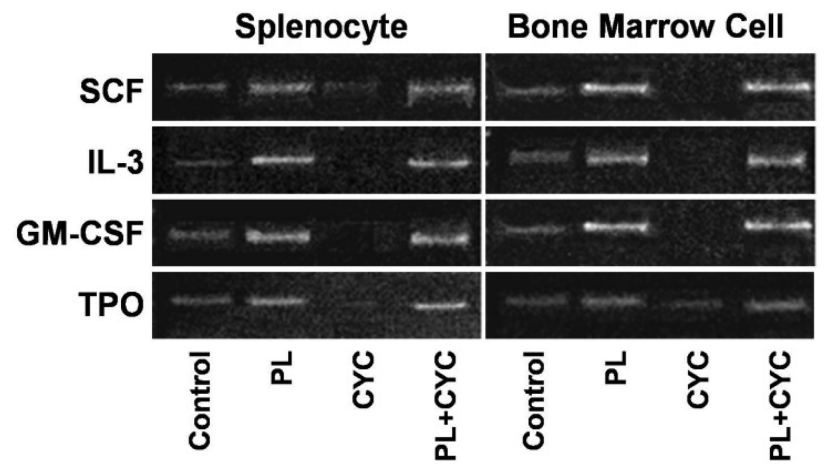

Fig. 3. PL increased the expression of mRNA for SCF, IL-3, GM-CSF, and TPO in spleen and bone marrow cells. Total RNA extracted from spleen and bone marrow cells that were treated $500 \mu \mathrm{g} / \mathrm{ml} \mathrm{PL}$ with or without $1.6 \mu \mathrm{g} / \mathrm{ml} \mathrm{CYC} \mathrm{for} 36 \mathrm{hr}$. The gene expression of SCF, IL-3, GM-CSF, and TPO was analyzed by RT-PCR.

the both cases of splenocytes and bone marrow cells, the presence of PL induces mRNA expression of hematopoietic factors and recovers the level of genes from inhibition that was caused by treatment of CYC. Taken together, our results demonstrate the PL stimulates the gene expression of SCF, IL-3, GM-CSF, and TPO that were the factors for hematopoietic proliferation and growth.

\section{DISCUSSION}

Radiotherapy and chemotherapy have been used frequently for overcoming cancer, but they can cause damage different tissues and organs (Ito et al., 1979). Myelosuppression and hematopoietic dysfunction are the most common side effect following radiation and chemotherapy so that these therapies must be used under severe controls of a drug dosage and a period of the treat (Chauvergne et al., 1996; Pronk et al., 1995; Cascinu et al., 1995). Therefore it is important in anti-cancer therapies to investigate the recovery of hematopoiesis from myelosuppression.

Phellinus linteus polysaccharide (PL) has potent antitumor activity and various biological activity such as immune cell proliferation, humoral and cellular immunity up-regulation (Pyo et al., 2001; Kim et al., 1996). Cyclophospamide (CYC) exerts antineoplastic effects via the alkylation of cellular components like nucleic acids, proteins, and others. Consequently, it can damage to normal tissues and organs including the hematopoietic system, the lung, and the liver. In the present work, we investigate the hematopoietic effect of PL in mouse splenocytes and bone marrow cells.

In the results of proliferation assay, there is a marked increase of the hematopoietic cell numbers on $48 \mathrm{hr}$ after PL treatment. Moreover PL enhanced the proliferation of cells in CYC-induced cytotoxic group (Fig. 1). PL is not showed to constrain the colony stimulation factors or substance like them (Fig. 2), but treatment with it increased the expression of SCF, IL-3, GM-CSF, and TPO mRNA in mouse splenocytes and bone marrow cells (Fig. 3). As a result, we conclude that PL can promote the hematopoiesis by up-regulation of the colony stimulation factors expression. Thus it can reduce myelosuppression and hematopoietic dysfunction that is the clinical complications following radiotherapy and chemotherapy.

\section{ACKNOWLEDGMENTS}

This research was supported by the Chung-Ang University Research Grants in 2004.

\section{REFERENCES}

Arai, K., Lee, F., Miyajima, A., Miyatake, S., Arai, N. and Yokota, T. (1990). Cytokines: coordinators of immune and inflammatory responses. Annu. Rev. Biochem. 59, 783-836.

Bociek, R. G. and Armitage, J. O. (1996). Hematopoietic growth factors. CA Cancer J. Clin. 46, 165-184.

Bokemeyer, C., Kuczyk, M. A., Kohne, H., Einsele, H., Kynast, B. and Schmoll, H. J. (1996). Hematopoietic growth factors and treatment of testicular cancer: biological interactions, routine use and dose-intensive chemotherapy. Ann. Hematol. 72, $1-9$.

Browder, I. W. (1983). Role of immunomudulation in surgical infection. Surv. Immunol. Res. 2, 299-301.

Brugger, W., Möcklin, W., Heimfeld, S., Berenson, R. J., Mertelsmann, R. and Kanz, L. (1994). Ex vivo expansion of enriched peripheral blood $\mathrm{CD} 34^{+}$progenitor cells by stem cell factor, interleukin-1 $\beta$ (IL-1 $\beta$ ), IL-6, IL-3, interferon- $\gamma$, and erythropoietin. Blood 81, 2579-2584.

Cascinu, S. (1995). Management of diarrhea induced by tumors or cancer therapy. Curr. Opin. Oncol. 7, 325-329.

Chauvergne. J., Chinet-Charrot, P., Stockle, E., Thomas, L. and Toulouse, C. B. (1996). Carboplatin and etoposide combination for the treatment of recurrent epithelial ovarian cancer. Bull. Cancer 83, 315-323.

Chihara, G., Hanuram, J., Maeda, Y., Arai, Y. and Fukuoka, F. (1969). Antitumor polysaccharide derive chemically from natural glucan (pachyman). Nature 225, 943-944.

Chung, K. S., Kim, S. S., Kim, H. S., Han, M. W. and Kim, B. K. (1994). Antitumor activity of $\mathrm{Kp}$, a protein-polysaccharide from the mycelial culture of Phellinus linteus. Chem. Pharm. Bull. 44, 1093-1095.

Clark, S. C. and Kamen, R. (1987). Hematopoietic growth factors as therapeutic agents. Science 236, 1229-1237.

Dexter, T. M., Allen, T. D. and Lajtha, L. G. (1997). Conditions controlling the proliferation of hematopoietic stem cells in 
vitro. J. Cell. Physiol. 91, 335-344.

Hirose, K. and Matsushima, K. (1993). The biological significance of the induction of mangnanse superoxide dismutase by interleukine 1 and tumor mecrosis factor. Free Radic. Clin. Med. 7, 71.

Ikegawa, T., Nakanishi, M., Uehara, N. and Chihara, G. (1968). Antitumor action of some basidomycetes, especially Phellinus linteus. Gann. 59, 155-157.

Ito, I., Inoue, T., Miyaishi, K., Mitsuhashi, N., Kimura, M., Takahashi, I., Maehara, Y. and Niibe, H. (1979). Radiotherapy of the esophageal cancer: initial radiation effect and prognosis on the basis of radiographic findings and histological subclassification types of squamous cell carcinoma. Rinsho Hoshasen $\mathbf{2 4}$ 915-921.

Jan, W., Visser-Dries, M. and Mulder, H. (1991). Culture of hematopoietic stem cell purified from murine bone marrow. Semin. Hematol. 28, 117-125.

Kao, I., Kobayashi, S., Yokokura, T. and Mutai, M. (1981). Antitumor activity of Lactobacillys casei in mice. Gann. 72, 517523.

Kim, H. M., Han, S. B., Oh, G. T., Kim, Y. H., Hong, D. H., Homg, N. D. and Yoo, I. D. (1996). Stimulation of humoral and cell mediated immunity by polysacchride from mushroom Phellinus linteus. Int. J. Immunopharmacol. 18, 295-303.

Mansell, P. W. A., Ichinose, H., Reed, R. H., Krementz, E. T., Mcnamee, R. and Di Luzio Jr, R. (1975). Macrophage-mediated destruction of human malignant cells in vitro. J. Natl. Cancer. Inst. 54, 571-580.

Naglieri, E., Gebbia, V., Durini, E., Lelli, G., Abbate, I., Selvaggi, F. P., Di Tonno, P. and Colucci, G. (1998). Standard
interleukin-2(IL-2) and interferon-alpha immunotherapy versus an IL-2 and 4-epirubicin immunochemotherapeutic association in metastatic renal cell carcinoma. Anticancer Res. 18, 2021-2026.

Pronk, L. C., Stoter, G. and Verweij, J. (1995). Docetaxel (Taxotere): single agent activity, development of combination treatment and reducing side-effects. Cancer Treat. Rev. 21, 463478.

Pyo, M. Y., Hyun, S. M. and Yang, K. S. (2001). Effect of Phellinus linteus Extracts on the Humoral Immune Responsc in Normal and Cyclophosphamide-treated mice. J. Appl. Pharmcol. 9, 194-200.

Rhee, Y. K., Han, M. J., Park, S. Y. and Kim, D. H. (2000). In vitro and in vivo antitumor activity of the fruit body of Phellinus linteus. Korea J. Food Sci. Technol. 32, 477-480.

Ridolfi, R., Flamini, E., Riccobon, A., De Paola, F., Maltoni, R., Gardini, A., Ridolfi, L., Medri, L., Poletti, G. and Amadori, D. (1998), Adjuvant adoptive immunotherapy with tumor-infiltrating lymphocytes and modulated doses of interleukin-2 in 22-patients with melanoma, colorectal and renal cancer, after radical metastasectomy, and in 12 advanced patients. Cancer Immunol. Immunother. 46, 185-193.

Sugiura, M. and Ito, H. (1977). Toxicological studies of Ganderma lucidum Karst. Tokyo Yakakyu Daigaku Kenkyu Nempo 27. $722-725$.

Takeda, T., Shibata, S. and Fukuoka, F. (1969). Further investigation of the structure and the antitumor activity of the polysaccharides from Gyrophora esculenta and Lasallia papulosa. Chem. Pharm. Bull. 17, 1910-1916. 